\title{
Gerçek Zamanlı Veri Takibinde Zamanın Modellenmesi
}

\author{
Onur Yolal $^{1 *}$, Tuğrul Artuğ ${ }^{2}$ \\ ${ }^{1}$ İstanbul Arel Üniversitesi, Fen Bilimleri Enstitüsü, Elektrik - Elektronik Mühendisliği, İstanbul, Türkiye (ORCID: 0000-0003-4609-0454) \\ 2 İstanbul Arel Üniversitesi, Mühendislik-Mimarlık Fakültesi, Elektrik - Elektronik Mühendisliği, İstanbul, Türkiye (ORCID: 0000-0002-9259-2458)
}

(Bu yayın HORA 2019 kongresinde sözlü olarak sunulmuştur.)

(İlk Geliş Tarihi 1 Ağustos 2019 ve Kabul Tarihi 24 Ekim 2019)

(DOI: 10.31590/ejosat.637768)

ATIF/REFERENCE: Yolal, O. \& Artuğ, T. (2019). Gerçek Zamanlı Veri Takibinde Zamanın Modellenmesi. Avrupa Bilim ve Teknoloji Dergisi, (Özel Sayı), 164-170.

\section{$\ddot{O} z$}

İnternete bağlanabilme yetisine sahip robotik cihazların, elektronik devrelerin ve bilgisayarların çalışmalarında ortak özellik zamana bağglılıktır. Veri aktarımının başladığı anda elektronik cihazlar ve sunucu arasında bir yoğunluk meydana gelmektedir. Bu yoğunluğun herhangi bir karışıklık yaratmadan sürdürülebilmesi ve haberleşmenin devreler ve sistemler arasında sağlanabilmesi için zamanın modellenmesine ihtiyaç duyulmaktadır. Gerçek zamanlı veri takibi ve veri alışverişine ilave olarak, birçok cihazın kontrol edilmesi gerektiğinde matematiksel ifadesi ve temsili olan zamana bağımlı bir modele ihtiyaç vardır.

Elektronik devrenin çalışmasının daima gerçek zamanlı takibi gerekmeyebilir. Bu takip gerçek zamanlı olmayabilir. Bu durum zaman modeline yerleştirilmek istendiğinde, o anın referansının alınabilmesi için elektronik devreden alınan veriler zaman modeline bir başlangıç zamanı belirlenerek insan kontrolüyle oturtulur. Elektronik devre çalıştıkça bir sürece sahip olur ve devrenin çalışması sona erdiğinde zaman modeli üzerinde bir son bulur. Meydana gelen ise elektronik devrenin verisiyle birlikte ona ait oluşan bir zaman parçasıdır.

Bir yıllık süre zarfının başında ve sonunda zaman modeli Dünya'nın yörüngesine benzeyecek şekilde bükülür ve artık doğrusal değildir; iki boyuttan çıkarak üç boyutlu bir şekil almıştır. Ortaya çıkan şekil günleri, ayları ve yılları simetrik ve sarmal bir yapıda temsil edecektir. Böylece zamana bağlı model insan tarafından kolayca anlaşılabilir.

Bu çalışmada bir elektronik devrenin çalıştığı tarihi, gerilimi, akımı ve direnç değeri gibi verileri geliştirilmiş bir Android uygulamasında simüle edildi. Sonuçlar internet aracılı̆ı̆yla web sitesinde gösterilmek üzere elektronik devrenin zaman modeline aktarıldı ve devrenin tüm verileri takip edildi. Tasarlanan zaman modeli 3 boyutlu sarmal yapıdadır. Ayrıca zaman modeli arayüzü ile ilgili elektronik devrenin geçmiş kayıt verilerine ulaşılarak, eski verileri elde etme ihtiyacına çözüm sunması amaçlanmıştır.

İnternet sayfasının trafiğini yönetmek sunucu tarafında bazı sorunları ve karışıklıkları beraberinde getirecektir. Yeni kullanıcılar sunucuda veri alışverişini yönetme konusunda sorunlara sebep olabilirler. Bunun giderilmesi için zaman modeli tasarımında alt zaman birimi olarak saniye seçilmektedir. Dolayısıyla milisaniye veya mikrosaniye düzeyinde çalı̧̧an bir sistem için zaman modeli üzerinde veri kayıpları meydana gelmesi kaçınılmazdır. Gelecek çalışmalarda internet sitesi üzerinde geliştirme çalışmaları yapılarak zaman modeline ait yeni sürümler geliştirilecektir.

Anahtar Kelimeler: Elektronik devreler, Zaman modeli, Nesnelerin interneti, Gerçek zamanlı veri takibi

\footnotetext{
* Sorumlu Yazar: İstanbul Arel Üniversitesi, Fen Bilimleri Enstitüsü, Elektrik - Elektronik Mühendisliği, İstanbul, Türkiye, ORCID: 0000-00034609-0454, bayyolal@gmail.com
} 


\title{
Time Modeling on Real-Time Data Tracking
}

\begin{abstract}
Robotic devices, electronic circuits, and computers which are able to connect internet have a common feature that is dependence to time. When data transfer begins, an increase of data density occurs between server and electronic devices. At this point, time should be modeled in order to maintain the density without any confusion and to ensure communication between circuits and systems. In addition to real-time data monitoring and data exchange, when multiple devices needed to get controlled, a time-dependent model is needed to have a mathematical expression and representation.
\end{abstract}

The operating of an electronic circuit may not always require real-time monitoring. It may also be offline or instant. In order to input data on a time model, a human based moderation may be required to handle the process by determining the start time of the event, and locating it on the time model. The electronic circuit has a process as it operates, and when the operation of circuit ends, it terminates on the time model. Then, there will be a piece of time related to the electronic circuit including its data.

At the beginning and the end of one-year period, the time model bends to resemble the Earth's orbit and it becomes no longer linear; it has changed into a three-dimensional shape. The generating shape will represent days, months, and years in symmetrical helix form so as to the time dependent model can be easily understandable by the human being.

In this study, the values of an electronic circuit such as date, voltage, current, and resistance simulated on developed an Android application. The results had transferred to electrical circuit's time model via internet on the web page in order to display, and had tracked all the data of the circuit. The designed time model was in 3D helix form. Moreover, accessing to the old records of the circuit by using time model interface in order to serve the need of achieving old data also aimed.

Managing the traffic of website may cause some difficulties and disruptions on server side. New users of website may cause some difficulties about managing data exchange on server. Hence, seconds are selected as the sub-unit of time model design. Therefore, data losses on the time model are inevitable for a system which is operating at the millisecond or microsecond levels. Future studies will be about improving the website to develop new versions of the time model.

Keywords: Electronic circuits, Time model, Internet of things, Real time data tracking

\section{Giriş}

Elektronik devreler, robotik cihazlar ve özel olarak üretilen internete bağlanabilme özelliğine sahip nesneler sürekli zamanlı veya ayrık zamanlı olarak çalışabilmektedir. Bir sistemin zamana bağlı olarak giriş değerleri ve çıkış değerleri ise matematiksel olarak ifade edilebilmektedir. Benzer şekilde simülasyonu yapılan bir elektronik devre üzerinden elde edilen verilerin grafiklerinin çizdirilmesine ihtiyaç duyulmaktadır. Bu şekilde devrelere ait değerlerin gözlemlerinin yapılması mümkün olmaktadır.

Ölçülen anlık değerlerin (gerilim, akım, direnç vb.) bir yerden başka bir yere aktarılmasıyla ilgili olarak sistemlerin kendi içlerinde birbirlerinden haberdar olabilmeleri için haberleşme sistemleri (internet, fiber optik kablo, kablosuz özelliği sunan antenler gibi) kullanılabilir. Bu elektronik devrenin haberleşme sistemlerine veri aktarımının sürekliliğinin sağlanması için Ethernet, Wi-Fi, kızılötesi haberleşme, Bluetooth gibi çeşitli haberleşme yöntemleri ile veri alışverişi sağlayan yapılara ihtiyaç duyulabilir. Ardından bu veri aktarımını bir merkezde sonlandıracak şekilde toplayacak alıcı ve kaydedici sunucu sistemlerin kullanılması gerekmektedir. $\mathrm{Bu}$ gereklilik gelen veri ve giden veri arasındaki koordinasyonu sağlamak üzere olabileceği gibi komut takibinin yapılması için de gerekli olabilir. Bu sistemin daha sonra insan-makina etkileşimini sağlamak adına bir arayüze sahip olması ve zamana bağlı olması gerekmektedir çünkü internete bağlanan bir cihaz gerçek zamanlı olarak çalışacaktır. İlgili arayüzde gelen veri zamana bağlı oldukça, gerçek zamanlı veri akışını sağlayacak ve insan tarafından bu akışın kontrol edilebilmesinin yolunu açacaktır.

Alman gökbilimci Johannes Kepler'in 1609 yılında yazdığı Astronomia Nova (The New Astronomy) isimli çalışması (Kepler, 1938) gezegenlere dair iki önemli konuyu açıklamıştır. Bunların ilki, gezegenlerin odak noktası olarak Güneş’in etrafında elips yörüngesi çizerek döndüğü hareket, diğeri ise gezegen ile Güneş arasında çizilen hayali bir çizginin her seferinde eşit alan taradığının gösterimidir. Sonraki çalışmalarında (Voelkel, 1999; Hawking ve Mlodinov, 2006) Kepler, gezegenlerin zaman içerisinde ilerlediğinde meydana gelen şekli "yörüngelerin ölçülerini meydana getirir” şeklinde açıklamıştır. "Orbit" ve "Satellite” kelimelerini literatüre kazandırarak okyanus gelgitlerinin sebebi olarak Ay’1 göstermiştir.

1982 yılında Hays ve araştırmacı ekip arkadaşları tarafından Unix sistemi için gerçek zamanlı işlem takibi ve kontrolü üzerine bir çalışma yayınlanmıştır (Hays vd., 1982). Unix üzerinde çoklu işlem mimarilerinin fonksiyonlarına göre ayrılmalarıyla çeşitli işlemlerin ve süreçlerin gerçek zamanlı olarak işlenmesine imkan tanınmakta olup gerçek zamanlı deney adıyla anılan özelleşmiş bir sistem parçasının klavye kontrolünü, diğer özelleşmiş sistem parçasının verilerinin hafizaya kaydedilmesini ve diğerlerinin benzer şekilde görevlere bölünmüş olan yapılarından bahsederek tüm işlem ve süreçlerin çevrimiçi grafiksel gösterimini oluşturmayı amaçlayan bir çalışma yapılmıştır. 
Nilsson, 1998 yılında gerçek zamanlı kontrol sistemleri üzerine bir tez yayınlamıştır (Nilsson, 1998). Çalışmasında haberleşme ağlarında kullanılan kontrol döngülerinden ve kontrol düğümlerinden bahsetmiştir. Algılayıcıların ve eyleyicilerin dağıtık ve gerçek zamanlı kontrol edilmesi üzerine çalışmıştır. Dağııık kontrol sistemlerinin güçlü olmasının yanında bazı önlemler alınması gerektirdiğinden bahsederek haberleşme ağlarına yönelik olarak "Markov Zincirini" kullanarak matematiksel modellemeleri formüllere dayandırmıştır.

2017 yılında Rankin, internete bağlanan cihazların telemetrik olarak sunucu tabanlı veri kontrolü üzerine bir çalışma yapmıştır (Rankin, 2017). Dağıtık enerji kaynaklarıyla (DER) ilgili elektrik enerjisi yönetimi, enerji dağıtımı, enerji sağlayıcı kaynaklar ve cihazlara yönelik özelleştirilmiş donanımsal ve yazılımsal çözüm sağlayan akıllı enerji yönetimi arayüzü üzerine çalışmışır. Günümüzün nesnelerin interneti kavramına uygun olarak elektrik enerjisinin yönetilmesi üzerine, hem maliyet düşürücü bir yaklaşım olmasıyla hem de işlemlerdeki karmaşıklığın basitleştirilmesine dair hesaplamalarıyla AllJoyn (Open Connectivity Foundation) adında açık kaynak kodlu yazılım arayüzünün kullanılmasının önemini göstermiştir.

Bu çalışmanın amacı, matematiksel olarak bir zaman modeli geliştirmek ve grafik olarak çizilmesini internet sitesinde sağlamaktır. Zamanı ifade etmeye ve zamanı temsil etmeye olabildiğince yakın bir zaman modeli tasarımı yaparak insanların zaman algısını kolaylaştırmak ve internet üzerinden veri alışverişini sağlayan cihazların yönetilmesini kolaylaştırmaktır. Bu çalışma ile bir elektronik devrenin internete bağlanarak algılayıcı verilerinin sunucuya aktarılmasının sağlanması ve sunucunun bu verileri zaman modeli üzerinde uygun şekilde yerleştirerek internet kullanıcısına göstermesi sağlanacaktır. İnternet erişimi, internet sitesinin barındırılmasını sağlayan bir sunucu ve kullanıcılar için hazırlanmış bir arayüz yardımı ile bir elektronik devrenin zaman yönetimi yapılabilecek, bu elektronik devrenin grafiklerinin çizilebilmesi sağlanabilecek ve zaman modeli üzerinde yerleşimi yapılabilecektir.

$\mathrm{Bu}$ çalışmada sadece dünyanın güneş etrafindaki hareketi sonucu meydana gelen yörünge esas alınmıştır. Zamanın üç boyutlu olarak ele alınmasıyla yeni bir modelin oluştuğu esas alınmıştır. Öte yandan, bir ayın 30 günden oluştuğu ve 1 günün 24 saatten meydana geldiği kabul edilerek zaman modelinin tasarlanması için matematiksel modelin ideal ve simetrik olması amaçlanmıştır. Zaman modelinin üç boyutlu olması planlanırken Kepler’in Dünya’nın yörüngesini açıkladığı çalışmalardan ilham alınmıştır.

Çalışma ikinci bölümde materyal ve metot ile devam etmektedir. Üçüncü bölüm araştırma sonuçları ve tartışmayı içermektedir. Çalışma son bölüm olan sonuç kısmı ile son bulmaktadır.

\section{Materyal ve Metot}

\subsection{Zamanın Modellenmesi}

Zamanın uzaydan bağımsız olmaması aynı zamanda gezegenlerin de zamandan bağımsız hareket edemeyeceklerini gösterir. Bir gezegen için zaman kendisini tekrar edecek şekilde olup belli bir periyoda sahiptir. Dünya gezegeninde olduğu gibi diğer gezegenler kendi ekseni etrafinda veya başka bir odak merkezi (güneş) etrafinda tur atabilirler ve bu esnada hareket halinde olduklarından her hareket anııın zamansal bir karşılığı vardır. Tıpkı mesafenin hıza bölünmesi gibi, zamanın meydana gelmesi ve bunun periyodik olarak yinelenmesi beklenir.

Bir modelin zaman modeli olarak adlandırılabilmesi için gösteriş biçiminin kabul görmesi gerekmektedir. İnsanoğlu için zaman kavramı, üzerinde yaşadığı dünya için olan ve ilerleyen zamandır. Bu ilerleme dolayısıyla geçmişi ve şimdiki anı taşıyacağı gibi geleceğin de varlığını işaret eder. Bu çalışmada zamanın parçaları olarak 60 saniye 1 dakika, 60 dakika 1 saat, 24 saat 1 gün, 30 gün 1 ay, 12 ay 1 yıl olarak kabul edilmiştir. Şubat ayı da 30 gün olarak kabul edilmiş olup zaman modelinin simetrik ve basitliği esas alınarak bir yılın 360 günden oluştuğu şekilde model çizilmiştir. Zaman modelinde zamanın ilerleyiş şeklini ifade etmek amacıyla saniyenin temel alınarak tamsayı halinde birer birer artacağı kabul edilmiştir. Bu yönüyle aslında zaman modeli üzerinde gerçek zaman değerleri örneklenerek modelin oluşturulmasında kolaylık ve simetriklik esas alınmıştır.

İlk dakikayı gösteren doğru parçası ile ikinci dakikayı gösteren doğru parçası arasına belirli bir açı verilerek büyük çerçeveden bakıldığında günler arasında ve aylar arasında bu açının daha çok netleştiği görülmektedir. Ay ve yıl temelli bakılmak istendiğinde zaman modelinin sarmal (helix) yapısı oluşmaktadır. Sarmal yapıda bir zaman modeli üzerinde başlangıç zamanı kolayca belirlenebilir, ancak bitiş zamanı net olarak belli olmayabilir. Çalışmasına devam eden bir elektronik devre için zaman modeline aktaracağı değerlerin sonsuz olduğu kabul edilerek, zamanın son değerinin de bitiminde ilerleyen bir zaman dilimi olduğu varsayılarak bu çalışmada zaman modelinin devamlılı̆̆ını ifade etmek üzere özel bir gösterim yapılmıştır. Eğer veri haberleşmesi devam ediyorsa ve başlanılan zamana denk gelecek şekilde veri alınmaya devam ediyorsa zaman modelinin üç boyutlu düzleminde z bileşen değerleri zaman modelindeki gösterimlere eklenmiş olacağı için Şekil 1'deki gibi sarmal bir görüntü oluşacaktır. 


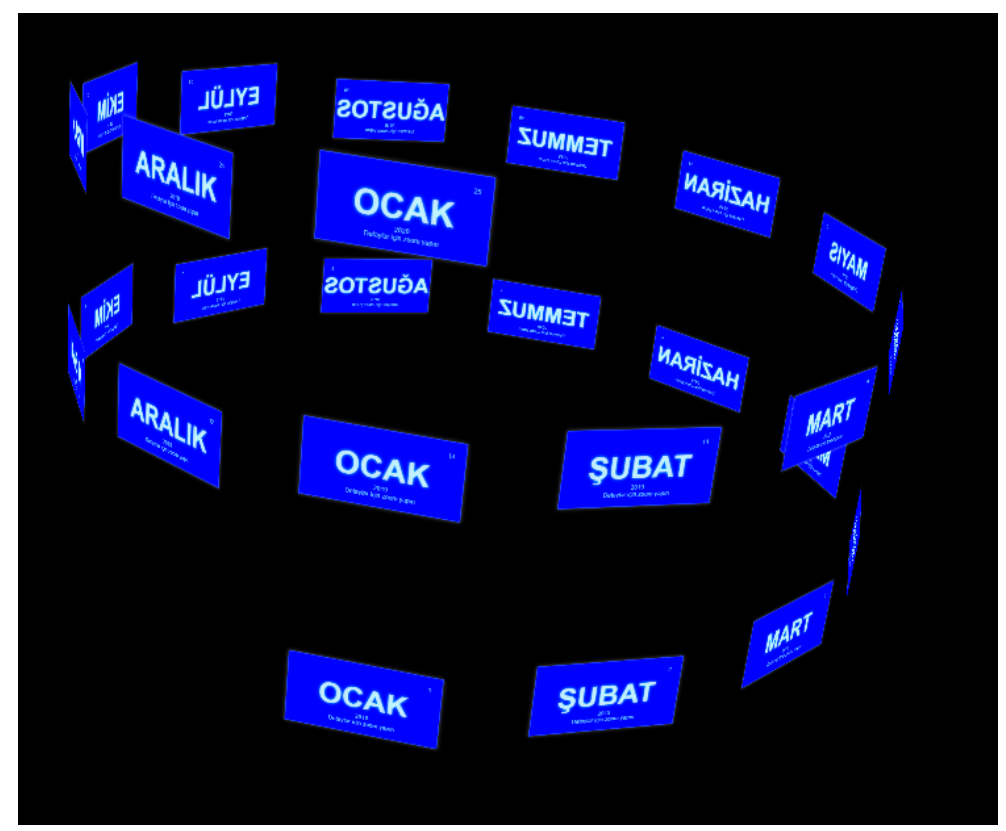

Şekil 1. Periyodu iki yıl olan örnek bir zaman modelinde aylık zaman gösterimi

Şekil 1'de gösterilen zaman modeli tasarımı başlangıç noktası ocak ayı olan ve bitiş ayı ocak ayı olan iki yıllık bir zaman modeli tasarımı olup yıl içerisindeki ayların tamamı kendi içlerinde ilerleyen zamanın açı değişimlerine göre bir model oluşumuna karşılık gelmektedir. Ay görünümlü zaman modeli aynı zamanda yıllık bazda da bir görünüm sunarak zaman modelini ifade etmektedir. Geçmiş kayıtların gösterimi aşağı yönde olup, ilerleyen zamanın yukarı yönde olduğu ifade edilen şekilde yeni aylar ait oldukları yeni yılları işaret etmektedir. Geniş açıdan bakılmak istendiğinde ise ayların ve yılların göründüğü zaman modeli üzerinde yakınlaştırma yapıldıkça zaman modeli, zamanın parçalarından olan alt birimlere doğru bir geçiş yapacaktır. Detaylı bir görünüm istendiğinde yakınlaştırma yapılarak Şekil 2'deki gösterim elde edilecektir.

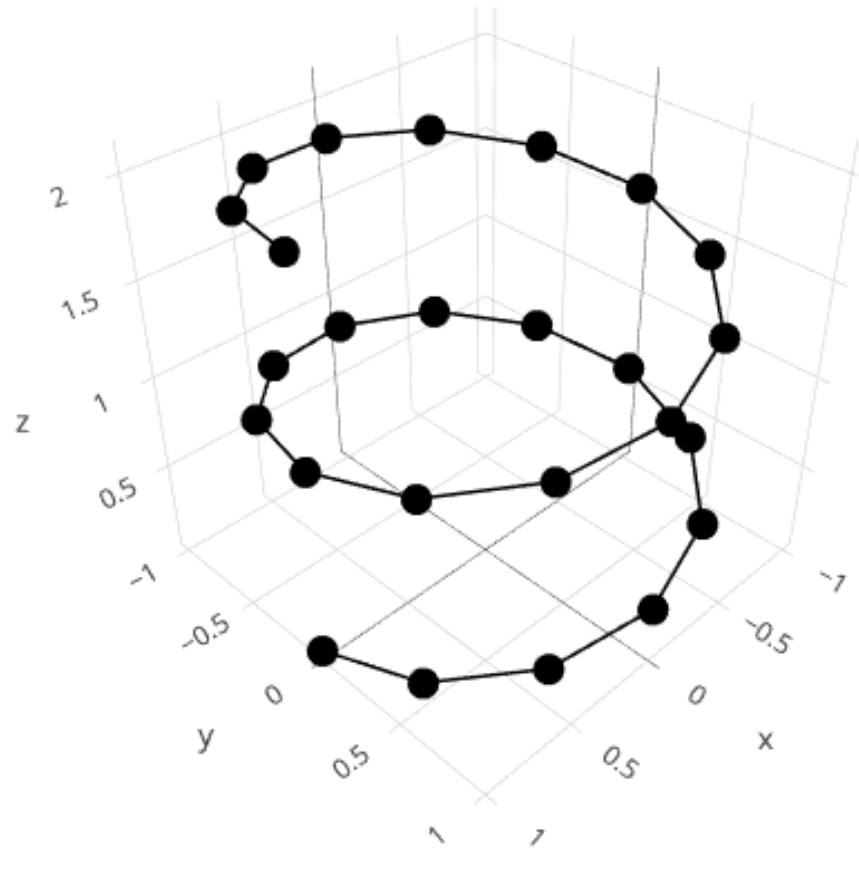

Şekil 2. Periyodu iki yıl olan örnek bir zaman modelinde detaylı aylık gösterim

Şekil 2'de gösterilen zaman modeli tasarımı başlangıç noktası ocak ayı olan ve bitiş ayı ocak ayı olan iki yıllık bir zaman modeli tasarımının noktasal bazda gösterimi olup aylara ait isimlendirme nokta ile aylar arasındaki günler ise çizgi ile noktalara (aylara) bağlanarak gösterilmiştir. Her bir nokta ilgili ayın adını gösterirken bir önceki ay ile arasında (x, y, z) olarak farklı konumlandırmaya sahiptir ve arasındaki açı ile model sarmal bir yapıya kavuşmuştur. İnternet sitesinde görüntülenen bu zaman modeli üzerine tıklandığında istenen tarih bilgisi görüntülenmektedir. Elektronik devrenin hangi tarihte çalıştı̆̆ bu şekilde geriye dönük olarak gözlemlenebilmekte ve geçmiş verisi elde edilebilmektedir.

Bir robotik parçanın çalışması veya bir elektronik devrenin çalışması Şekil 2'de gösterilen basitleştirilmiş zaman modeli görünümünde gösterilmek istendiğinde gereken şeyler bu elektronik devrenin hangi gerçek zaman anında çalıştığı ve çalışırken hangi 
verilerin alındığı ile hangi komutun elektronik devreye gönderilmesi gerektiğidir. Zaman modeli gelecek zamanlar için elektronik devreye komut gönderme özelliğine sahip olacağı için en alt zaman birimi olarak saniye seçildiğinden dolayı saniye temelli olarak komut gönderebilmeye imkân sağlayacaktır. Örneğin bir robotik kol uygulamasında kolun hangi zaman değerinde hangi konuma sahip olacağı zaman modeli üzerinde konumlandırılabilecek olup bu komut akışına göre zaman modelinde noktalar oluşturulabilecektir.

\section{2. İnternet Sitesi ve Android Uygulaması}

İnternet sitesine ait olan zaman modeli tek değildir. Her farklı cihazın kendine has bir zaman döngüsü ve kendisine ait y1llık periyodunun sona erme süresi olacağı için farklı zaman modeli yapıları oluşturabilmek mümkündür. Bunun için hazırlanan internet sitesinde kullanıcı adı ve şifre ile giriş yapıldıktan sonra sunucu üzerinde birden fazla elektronik devre için yeni zaman modeli oluşturulabilir. Ardından tanımlayıcı bilgiler ve bağlantı ayarları yapıldıktan sonra gelen veya gönderilen ilk verinin gerçek zamanlı olarak zaman modeline işlenmesinin ardından şimdiki zamanın gösterimi ile başlayan ve sona ermeyecek şekilde (aksi bir komut gelmediği takdirde) ilerleme kaydeden ve değer gösteren bir yapı elde edilmiş olur.

Android Studio programı [http1] kullanılarak Java kodları yazılan Android uygulaması üzerinde hazırlanan gerilim kaynağı, anahtar, direnç ve yükten oluşan seri bağlı bir elektronik devrenin başlangıç parametrelerinin kullanıcı tarafindan girilmesi istenmektedir. Başlangıç parametreleri ile birlikte zamanın gerçek zamanlı olarak gösterim anına uygulamada yer verilmiş olup, kullanıcı Şekil 3 'te gösterilen uygulamada sol altta konumlandırılmış "RUN" düğmesine her bastığında elektronik devre uygulaması, o zamana ait verileri elde edip bir dosyaya kaydedecektir. Bu şekilde ilk 10 değere kadar kayıt alınmasına bu uygulama için imkan tanınmış olmaktadır (yalın bir simülasyon için yalnızca on değer esas alınmıştır). Eğer 10'dan daha az kayıt yeterliyse "End Save File" düğmesi ile kaydın istenilen zamanda sonlandırılmasına imkan tanınmaktadır. Kayıt tamamlandıktan sonra dosya uzantısı (.csv) olan veri dosyası oluşturulmaktadır. Ardından bu dosyanın internet sitesine gönderimi sağ alt köşede yer alan "Upload To Website" düğmesi ile sağlanmaktadır. Böylelikle simülasyonu yapılan elektronik devreye ait veriler oluşmuş olup zaman modeline aktarılmaya hazır hale getirilmiştir.

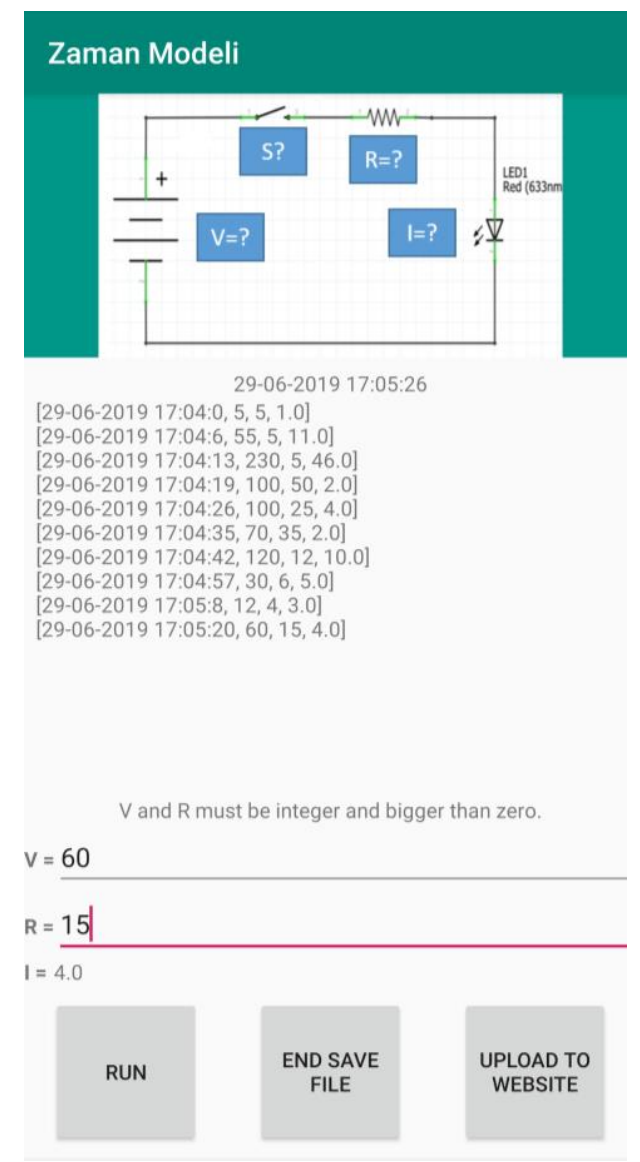

Şekil 3. Geliştirilen Android uygulaması ile bir elektronik devreden veri elde edilmesi

$\mathrm{Bu}$ çalışmanın (.csv) uzantılı dosyasının internet sitesinin sunucusuna yüklenmesinin ardından internet sitesindeki zaman modelinin oluşumu birtakım aşamalardan sonra gerçekleşmektedir. Açık kaynak kodlu Plot.ly kütüphaneleri [http2] Javascript kodlarını destekleyerek grafik çizilmesini mümkün kılmaktadır. İnternet sitelerinin tasarımları için temel kod kaynakları sunan w3schools.com [http3] tarafından HTML ve CSS kodlamalarında bilgi ihtiyacı karşılanarak oluşturulan üç boyutlu zaman modeli üzerinde verilerin konumlandırılması Şekil 4'te gösterildiği gibi olmaktadır. 


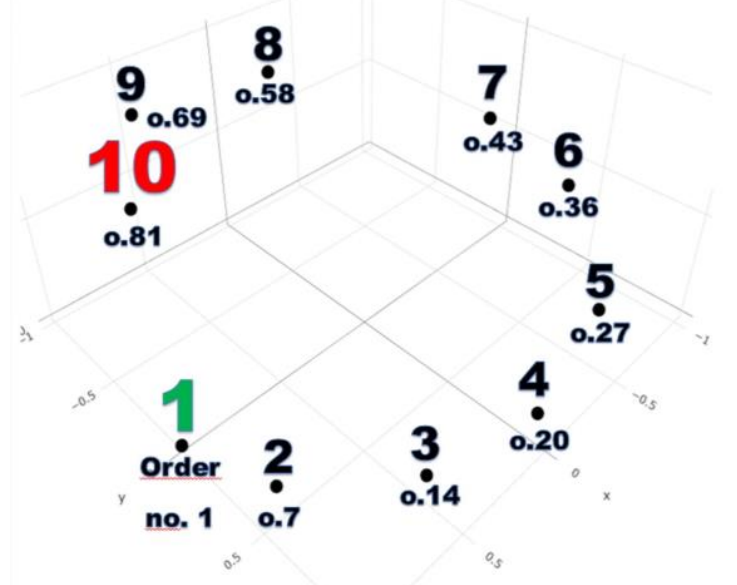

Şekil 4. Zaman modeli üzerinde elektronik devreye ait verilerin konumlandırılması

Veriler zaman modeline aktarılırken bir sıra numarası (Order no.) tanımlanmıştır. Bu tanımlamada, alınan her anlamlı verinin alındığı andaki süresi saniye cinsinden zaman modeline yansıtılmıştır. Örneğin Şekil 4 'te gösterilen ve sıra numarası 2 olarak gösterilen nokta başlangıç değerinden 6 saniye sonrasında elektronik devreden alınmış olup yedinci saniyeye denk gelecek şekilde zaman modeline aktarılmıştır. Toplamda örnek amaçlı 10 adet veri alımı ile sınırlandırılan bu elektronik devre simülasyonunda, her bir veriye denk gelen saniye numaraları nokta gösteriminin altında yer almaktadır. Buna göre sıra numarası dört olan veri kaydı aslında simülasyonun yirminci saniyesinde, sıra numarası beş olan veri kaydı ise simülasyonun yirmi yedinci saniyesinde alınarak zaman modeli üzerinde gösterilmiştir. Bu özellik kullanıcı tarafından kapatılabilir veya yeniden açılabilir.

\section{Araştırma Sonuçları ve Tartışma}

\subsection{Zaman Modeliyle Verilerin İnternet Sitesi Üzerinden Takibi}

Bu çalışmada geliştirilen örnek bir Android uygulaması ile simülasyon yapılan bir elektronik devreye ait tarih, gerilim, akım ve direnç değerleri sayısal olarak elde edilerek (.csv) uzantısına sahip bir dosyaya kaydedilmiştir. Ardından bu dosyadaki verilerin internet sitesinde zaman modeli üzerinde görüntülenebilmesi için veriler internet sitesine Şekil 3'teki uygulama kullanılarak aktarılmıştır.

İnternet kullanıcısı tarafından söz konusu elektronik devreye ait olan sayfa görüntülendiğinde cihazdan elde edilen on farklı zamanda alınan veriler Şekil 4'te gösterilmektedir. Bu şekilde veriler zaman sıralı olarak artarda ve hesaplanmış konumlarda dizilmekte ve üç boyutlu olarak zaman modeli üzerinde ilgili kayıt için yakından bakma özelliği sağlanmaktadır.

Zaman modeli üzerine gelen ilk veri zaman modelinin başlangıç anı olarak, elde edilen son veri ise modelde son değere denk gelecek şekilde belirlenmiştir. Veri aktarımı sonucu oluşan zaman modeli üç boyutlu bir yapı kazanarak görsel olarak ifade sağlayacak şekilde Şekil 4'te gösterilerek internet sitesinin sunucusuna kaydedilmiştir.

Eğer aynı elektronik devre simülasyonu üzerinde ilerleyen zamanlarda değer gelmeye devam ederse bir sonraki gelen veri bu örnek için on birinci sıraya denk geleceğinden zaman modelinde ikinci periyoda yerleştirilecektir. Bu gösterimin sebebi elektronik devrenin çevriminin ilk periyotta belirlenmiş olması ve yeni gelen verinin artık bu periyoda sığamayacağından dolayı bir sonraki periyotta gösterilmeye başlanacak olmasıdır. Artık elektronik devrenin çalışma periyodu ortaya saniye bazında çıkmıştır. Farklı bir elektronik devre simülasyonu uygulamasında periyot, saniye yerine dakika, saat, gün, ay, yıl şeklinde olabilir. Dünya'nın güneş etrafındaki dönüşünü 360 günde tamamladığının, zaman modeli için başlangıçta kabul edilmesinden dolayı elektronik devrenin on birinci verisi dünya zamanına göre kendisinin ikinci senesine denk gelecektir. Bu şekilde zaman modeli üzerinde yukarı doğru ilerleme, devreden gelen verilerle gerçekleşecek ve gösterimi yapılacaktır.

Hays ve diğerlerinin çalışmasından (Hays vd., 1982) farklı olarak bu çalışmada zaman modeli üzerinde aynı anda birden fazla işlemin takip edilebilmesi için aynı zaman modeli üzerinde tek bir elektronik devre veya farklı elektronik cihazlar için farklı zaman modelleri ile farklılıklarının gösterilmesi gerektiği ihtiyacı anlaşılmıştır.

Yapılan çalışma için Nilsson tarafından ifade edilen ana fikirden yola çıkılarak (Nilsson, 1998), tek bir bağlantı yolu vasıtasıyla birden fazla elektronik devre için elde edilmek istenen verilerin aynı anda zaman modeline kayıt edilmesi noktasında sunucu tarafındaki zorlukların oluşacağı görülmüştür. Aynı anda birden fazla elektronik devrenin tek zaman modeline veri kaydetmesinin gösterilebilmesi için ilerleyen çalışmalarda zaman modeli arayüzünde optimizasyon çalışmaları yapılacaktır.

Rankin'in yaklaşımı (Rankin, 2017) ile çalışmanın ilerleyen aşamasında farklı platformlara uygunluk ve veri takibinde optimizasyonların yapılmasında uluslararası kabul görmüş teknolojik çözüm yapılarının kullanılması gerektiği görülmüştür. Bu şekilde bir kullanıcı zaman modeli üzerindeki işlemleri diğer platformlara aktarırken veya veri taşımak isterken olası sorunların giderilmesi üzerine yazılımsal testlerin yapılması ve olası hataların giderilmesi gerekmektedir. 


\section{Sonuç}

$\mathrm{Bu}$ çalışma sonucunda, içeriğinde kişiselleştirilebilen zaman modeli tasarımı barındıran bir internet sitesi, internete bağlanabilen her elektronik devre için komut yönetimi, gelen elektronik devre verilerinin kontrolü ve takibi sağlanmıştır. Tasarlanan bu internet sitesi, içerisinde elektronik devre için kendisine ait değerleri ve komutları barındıracak şekilde özelleştirilmiş bir yapıyı içerir. Zamanın saniye ile yıl arasındaki anlarının internet bağlantısı kurabilen (IoT) cihazlar için kaydedilmesi vasıtasıyla geçmişe dönük olarak verilerin görüntülenmesi sağlanmaktadır.

İnternet sitesi üzerinde zaman modelinin insanın anlayabileceği şekilde modellenebilmesi için Kepler'in ortaya koymuş olduğu yörünge denklemlerinden yola çıkarak dünyanın güneş etrafındaki hareketleri uyarınca zamansal olarak basitleştirilmiş, sarmal yapıda, üç boyutlu ve simetrik bir zaman modeli tasarlanmıştır. Zaman modeli üzerindeki her bir saniye başta olmak üzere dakika, saat, gün, ay ve yıl tanımlamalarına zaman modeli üzerinde yer verilerek aslında elektronik devreler için anlamsız olan ancak internet sitesi üzerinden yönetim paneliyle giriş yapıp veri akışııı gözlemleyen kullanıcı için anlamlı olacak şekilde bir yapı tasarlanmıştır.

Zamanın yalnızca sayı doğrusu üzerindeki gösterimler gibi geçmişten geleceğe doğru ilerlemediğini, dünyanın güneş etrafindaki hareketinin periyodik süreci içerisinde meydana gelen zaman oluşumunun, zaman modeli tasarımında işaret ettiği grafiksel modellemelerin üç boyutlu olarak oluşturulmasında yol gösterici olduğu düşünülmüştür. Bu çalışmada ortaya konulan yenilik zaman algısının yalnızca doğrusal olmayabileceği, aynı zamanda belli bir periyoda sahip olacak şekilde üç boyutlu bir yapıda modellenebileceğidir.

Gelecek çalışmalarda internet sitesi üzerinde kod iyileştirme çalışmaları yapılarak zaman modeline ait yeni sürümler geliştirilecektir. Bu yeni sürümlerde kullanııı sayısının artması durumunda sunucularda performans artışının yapılması ve saniyenin alt birimlerinde veri takibinin yapılması üzerine çalışılacaktır. Ayrıca sunucu ve internet sitesinin yapısal tasarımında kullanıcı arayüzü ve deneyimi üzerine çalışlarak iyileştirmeler yapılacak olup olası internet saldırılarında veri kaybının ve kullanıcı verilerinin muhafaza edilmesi üzerine çalışlacaktır.

\section{Kaynakça}

Kepler, J. (1938). Astronomia Nova. Münih, Almanya: Herausgeben Von Max Casper.

Voelkel, J. R. (1999). Johannes Kepler and the New Astronomy. USA: Oxford University Press.

Hawking, S., Mlodinov, L. (2006). Zamanın Daha Kısa Tarihi. Doğan Kitap.

Hays, A.V. Jr., Richmond, B. J., \& Optican, L. M. (1982). Unix-based multiple-process system, for real-time data acquisition and control. El Segundo, CA, USA: Electron Conventions.

Nilsson, J. (1998). Real-Time Control Systems with Delays. Bitirme Tezi. Department of Automatic Control, Lund Institute of Technology (LTH).

Rankin, L. (2017). An Open Source Extensible Smart Energy Framework. USA: doi:10.2172/1347747.

[http1] https://developer.android.com/studio

[http2] https://plot.ly

[http3] https://www.w3schools.com/ 